\title{
The evolving epidemiology of Clostridium difficile infection in Canadian hospitals during a postepidemic period (2009-2015)
}

\author{
Kevin C. Katz MD, George R. Golding PhD, Kelly Baekyung Choi MSc, Linda Pelude MSc, \\ Kanchana R. Amaratunga MD, Monica Taljaard PhD, Stephanie Alexandre BA, Jun Chen Collet MSc, \\ Ian Davis MD, Tim Du MSc, Gerald A. Evans MD, Charles Frenette MD, Denise Gravel MSc, Susy Hota MD, \\ Pamela Kibsey MD, Joanne M. Langley MD, Bonita E. Lee MD, Camille Lemieux MD, Yves Longtin MD, \\ Dominik Mertz MD, Lorraine Maze Dit Mieusement MN, Jessica Minion MD, Dorothy L. Moore MD, \\ Michael R. Mulvey PhD, Susan Richardson MD, Michelle Science MD, Andrew E. Simor MD, Paula Stagg MN, \\ Kathryn N. Suh MD, Geoffrey Taylor MD, Alice Wong MD, Nisha Thampi MD; for the Canadian Nosocomial \\ Infection Surveillance Program
}

Cite as: CMAJ 2018 June 25;190:E758-65. doi: 10.1503/cmaj.180013

Visual abstract available at www.cmaj.ca/lookup/suppl/doi:10.1503/cmaj.180013/-/DC2

\begin{abstract}
BACKGROUND: The clinical and molecular epidemiology of health care-associated Clostridium difficile infection in nonepidemic settings across Canada has evolved since the first report of the virulent North American pulsed-field gel electrophoresis type 1 (NAP1) strain more than 15 years ago. The objective of this national, multicentre study was to describe the evolving epidemiology and molecular characteristics of health care-associated $C$. difficile infection in Canada during a post-NAP1epidemic period, particularly patient outcomes associated with the NAP1 strain.
\end{abstract}

METHODS: Adult inpatients with $C$. difficile infection were prospectively identified, using a standard definition, between 2009 and 2015 through the Canadian Nosocomial Infection Surveillance Program (CNISP), a network of 64 acute care hospitals. Patient demographic charac- teristics, severity of infection and outcomes were reviewed. Molecular testing was performed on isolates, and strain types were analyzed against outcomes and epidemiologic trends.

RESULTS: Over a 7-year period, 20623 adult patients admitted to hospital with health care-associated $C$. difficile infection were reported to CNISP, and microbiological data were available for 2690 patients. From 2009 to 2015, the national rate of health care-associated $C$. difficile infection decreased from 5.9 to 4.3 per 10000 patient-days. NAP1 remained the dominant strain type, but infection with this strain has significantly decreased over time, followed by an increasing trend of infection with NAP4 and NAP11 strains. The NAP1 strain was significantly associated with a higher rate of death attributable to $C$. difficile infection com- pared with non-NAP1 strains (odds ratio $1.91,95 \%$ confidence interval [Cl] 1.292.82). Isolates were universally susceptible to metronidazole; one was nonsusceptible to vancomycin. The proportion of NAP1 strains within individual centres predicted their rates of health careassociated $C$. difficile infection; for every $10 \%$ increase in the proportion of NAP 1 strains, the rate of health care-associated C. difficile infection increased by $3.3 \%$ (95\% Cl 1.7\%-4.9\%).

INTERPRETATION: Rates of health careassociated $C$. difficile infection have decreased across Canada. In nonepidemic settings, NAP4 has emerged as a common strain type, but NAP1, although decreasing, continues to be the predominant circulating strain and remains significantly associated with higher attributable mortality. lostridium difficile infection is the most common infectious cause of health care-associated diarrhea among hospitaladmitted patients in developed countries and can lead to substantial morbidity and mortality. ${ }^{1,2}$ In 2002, an outbreak in Quebec, Canada, demonstrated the emergence of a virulent strain type known as the North American pulsed-field gel electrophoresis type 1 (NAP1; associated with ribotype 027). ${ }^{3}$ This strain type was associated with increases in the number of $C$. difficile outbreaks with higher rates of death and recurrence. ${ }^{4-8}$ However, the data suggesting that the NAP1 strain is associated with more complicated disease 
were primarily based on studies related to larger institutional and regional outbreaks. ${ }^{7,9-11}$ Since other strains have also been found to be associated with complicated outcomes, ${ }^{12,13}$ the association of NAP1 with severe disease or higher rates of health care-associated C. difficile infection in nonepidemic settings is less clear.

In Canada, national-level data on health care-associated C. difficile infection are collected through the Canadian Nosocomial Infection Surveillance Program (CNISP), a collaborative effort of the Public Health Agency of Canada and sentinel hospitals across the country that participate as members of the Canadian Hospital Epidemiology Committee, a subcommittee of the Association of Medical Microbiology and Infectious Disease Canada. The data collected provide a measure of the burden of illness, establish benchmarks for comparison and identify potential trends of disease. The objectives of this national, multicentre study were to describe the evolving epidemiology and molecular characteristics of health care-associated $C$. difficile infection in Canada during a postepidemic period, and to examine the effect of NAP1 strain type on patient outcomes and institutional rates of health careassociated $C$. difficile infection over time.

\section{Methods}

\section{Data sources and population}

Prospective surveillance for health care-associated C. difficile infection among hospital-admitted patients in Canada has been conducted by the CNISP since 2007. By 2015, the CNISP included a network of 64 acute care hospitals across the 10 provinces (Appendix 1, available at www.cmaj.ca/lookup/suppl/doi:10.1503/ cmaj.180013/-/DC1). ${ }^{14}$ Of these, 13 are large acute tertiary care hospitals with more than 500 beds available within the facility, 32 hospitals are of intermediate size (201 to 500 beds) and the remaining 19 hospitals are smaller facilities with fewer than 200 beds.

This study used data from adult-only and mixed (adult and pediatric combined) hospitals that participated in surveillance of health care-associated C. difficile infection from 2009 to 2015. Pediatric stand-alone hospitals were excluded.

The rate calculation of health care-associated $C$. difficile infection included only data on infection from adult-only and mixed hospitals that provided both the number of cases and patient-days. It was not possible to separate out the pediatric denominator data from these mixed hospitals. This resulted in the inclusion of 346 ( $2 \%$ of all cases) pediatric cases in the rate calculation of health care-associated $C$. difficile infection, but these were excluded from any further analysis.

\section{Case definitions}

Case definitions for $C$. difficile infection have been previously described. ${ }^{15}$ In brief, surveillance for health care-associated C. difficile infection is based on a positive laboratory confirmation of $C$. difficile infection and a compatible clinical syndrome developing 72 hours or longer after admission, or less than 72 hours after admission if patients had been previously admitted to the admitting hospital and discharged within the previous 4 weeks. Severe outcomes were defined as admission to the intensive care unit, colectomy or death within 30 days associated with a positive test for $C$. difficile infection. All deaths were reviewed by a physician to determine whether the death was attributable to $C$. difficile infection.

\section{Data collection}

The medical records for cases of health care-associated $C$. difficile infection were reviewed for clinical, demographic and outcome data, and a standardized form was completed. Clinical and demographic data were collected throughout the year, and severe outcome information, $\boldsymbol{C}$. difficile molecular typing and susceptibility testing of consecutive nonduplicate isolates were undertaken for cases occurring between Mar. 1 and Apr. 30 annually.

The data were collected by hospital staff (infection-control professionals) and then submitted through a secure online platform that has built-in logic to prevent many common data-entry errors. Once data were submitted, the Public Health Agency of Canada's epidemiologist validated and cleaned the data, and followed up as needed.

\section{Laboratory methods}

Between 2009 and 2015, stool samples from eligible patients admitted to hospital were sent to the National Microbiology Laboratory (Winnipeg, Man.) for C. difficile isolation using ethanol shock treatment. Toxigenic strains, as confirmed by polymerase chain reaction, were further characterized using pulsed-field gel electrophoresis and antimicrobial susceptibility testing as previously described. ${ }^{5}$

\section{Statistical analysis}

Rates of health care-associated $C$. difficile infection were calculated as the number of cases per 10000 patient-days. For reporting purposes and to ensure confidentiality, we grouped the provinces into 3 regions: west (British Columbia, Alberta, Saskatchewan and Manitoba), central (Ontario and Quebec) and east (Nova Scotia, New Brunswick, Prince Edward Island, and Newfoundland and Labrador). To assess significant trends over time for patient characteristics, laboratory and severe outcome results, we used the Cochran-Armitage test for categorical variables and the Mann-Kendall test for continuous variables.

To compare characteristics of the groups of patients with NAP1 versus all other strains (non-NAP1), we used the $\chi^{2}$ test for categorical variables and the Student $t$ test or the Wilcoxon ranksum test for continuous variables.

Logistic regression analyses were performed to determine the independent association between the strain types and outcomes (all-cause death or death attributable to $C$. difficile infection). Death attributable to $C$. difficile infection is defined as death directly and indirectly related to $C$. difficile infection. Covariates (i.e., sex, age, albumin level and leukocyte count) used in the regression models were specified a priori. Covariates were dichotomized as female versus male sex; age group 18-64 years versus 65 years or older; albumin level greater than $30 \mathrm{~g} / \mathrm{L}$ versus $30 \mathrm{~g} / \mathrm{L}$ or less; and leukocyte count greater than $15 \times 10^{9} / \mathrm{L}$ versus $15 \times 10^{9} / \mathrm{L}$ or less.

To assess the relation between the proportion of NAP1 strains in individual hospitals and the reported institutional rate of health care-associated $C$. difficile infection, a generalized linear model was used with Poisson distribution and log-link function. The unit of analysis was the individual hospital. The model included year, 
hospital size (beds) and region (west, central and east) as fixed effects and the natural log of patient days as an offset term. The model was estimated using generalized estimating equations with an autoregressive correlation structure to accommodate correlations in the repeated-measures on the same hospital over time.

All statistical analyses were conducted using SAS (release 9.3, SAS Institute) software with a significance level of 0.05 .

\section{Ethics approval}

The study was approved by the research ethics boards at participating sites as required by institution-specific policies.

\section{Results}

A total of 20623 cases of health care-associated C. difficile infection was reported by adult-only and mixed participating hospitals from 2009 to 2015. The number of participating hospitals ranged from 42 to 53 during the 7-year study period (Table 1), excluding pediatric stand-alone hospitals.

Most cases were detected in hospitals with more than 200 beds; $53.2 \%$ of cases were from centres with $201-500$ beds and $44.1 \%$ were from hospitals with more than 500 beds. Over the 7-year surveillance period, a downward trend was noted in national rates of health care-

Table 1: Patient characteristics, clinical results and severe outcomes of 17202 adults diagnosed with health care-associated Clostridium difficile infection from 2009 to $2015^{\star}$

\begin{tabular}{|c|c|c|c|c|c|c|c|c|}
\hline Variable & 2009 & 2010 & 2011 & 2012 & 2013 & 2014 & 2015 & 2009-2015 \\
\hline \multicolumn{9}{|l|}{ Year-round surveillance } \\
\hline No. of hospitals & 42 & 44 & 46 & 45 & 45 & 51 & 53 & - \\
\hline No. of patients $†$ & 1627 & 2307 & 2795 & 2645 & 2746 & 2593 & 2489 & 17202 \\
\hline Sex, female, no. (\%) & $766(48.0)$ & $1178(51.3)$ & $1456(52.3)$ & $1275(48.4)$ & $1350(49.2)$ & $1270(49.0)$ & $1216(48.9)$ & $8511(49.7)$ \\
\hline Age, yr, mean \pm SD & $69.6 \pm 16.2$ & $70.4 \pm 16.4$ & $69.4 \pm 17.1$ & $69.7 \pm 16.6$ & $68.9 \pm 17.0$ & $68.2 \pm 17.1$ & $68.1 \pm 16.8$ & $69.2 \pm 16.8$ \\
\hline \multicolumn{9}{|l|}{ Age group, yr, no. (\%) } \\
\hline $18-64$ & $534(32.8)$ & $723(31.4)$ & $961(34.4)$ & $851(34.5)$ & $947(34.5)$ & $939(36.2)$ & $923(37.1)$ & $5878(34.2)$ \\
\hline$\geq 65$ & $1092(67.2)$ & $1580(68.6)$ & $1830(65.6)$ & $1793(67.8)$ & $1796(65.5)$ & $1654(63.8)$ & $1566(62.9)$ & $11311(65.8)$ \\
\hline $\begin{array}{l}\text { Time to } C \text {. difficile test from the date of } \\
\text { admission, } d \text {, median (IQR) }\end{array}$ & $13(6-30)$ & $13(6-27)$ & $12(6-27)$ & $12(6-26)$ & $12(7-25)$ & $12(7-25)$ & $10(5-21)$ & $12(6-26)$ \\
\hline $\begin{array}{l}\text { Patients diagnosed with health care- } \\
\text { associated C. difficile infection on } \\
\text { readmission, no. (\%) }\end{array}$ & $170(10.4)$ & $296(12.8)$ & $336(12.0)$ & $301(11.4)$ & $405(14.7)$ & $333(12.8)$ & $421(16.9)$ & $2262(13.1)$ \\
\hline \multicolumn{9}{|l|}{ March and April targeted surveillance } \\
\hline No. of cases & 559 & 478 & 564 & 532 & 543 & 531 & 477 & 3684 \\
\hline \multicolumn{9}{|l|}{ Clinical results } \\
\hline Temperature, ${ }^{\circ} \mathrm{C}$, mean \pm SD & $37.1 \pm 0.8$ & $37.1 \pm 0.8$ & $37.1 \pm 0.8$ & $37.2 \pm 0.8$ & $37.0 \pm 0.7$ & $37.2 \pm 0.8$ & $37.2 \pm 0.7$ & $37.1 \pm 0.8$ \\
\hline $\begin{array}{l}\text { Leukocyte count, } \times 10^{9} / \mathrm{L} \text {, } \\
\text { median (IQR) }\end{array}$ & $\begin{array}{c}13.0 \\
(8.3-18.4)\end{array}$ & $\begin{array}{c}11.3 \\
(8.0-16.2)\end{array}$ & $\begin{array}{c}11.1 \\
(7.0-16.6)\end{array}$ & $\begin{array}{c}11.2 \\
(7.7-16.5)\end{array}$ & $\begin{array}{c}10.9 \\
(7.0-16.5)\end{array}$ & $\begin{array}{c}11.3 \\
(7.4-16.8)\end{array}$ & $\begin{array}{c}12.3 \\
(7.7-17.7)\end{array}$ & $\begin{array}{c}11.5 \\
(7.7-16.9)\end{array}$ \\
\hline Albumin, g/L, median (IQR) & $\begin{array}{c}26.0 \\
(21.0-30.0)\end{array}$ & $\begin{array}{c}27.0 \\
(22.0-31.0)\end{array}$ & $\begin{array}{c}27.0 \\
(22.0-32.0)\end{array}$ & $\begin{array}{c}26.0 \\
(22.0-31.0)\end{array}$ & $\begin{array}{c}25.0 \\
(21.0-29.0)\end{array}$ & $\begin{array}{c}26.0 \\
(21.0-30.5)\end{array}$ & $\begin{array}{c}25.0 \\
(21.0-31.0)\end{array}$ & $\begin{array}{c}27.0 \\
(23.1-31.0)\end{array}$ \\
\hline \multicolumn{9}{|l|}{ Severe outcomes within $30 \mathrm{~d}$, no. (\%) } \\
\hline \multicolumn{9}{|l|}{ ICU admission } \\
\hline All-cause & $4(7.7)$ & $27(5.8)$ & $35(6.4)$ & $30(5.7)$ & $46(8.5)$ & $30(5.7)$ & $41(9.8)$ & $251(7.0)$ \\
\hline $\begin{array}{l}\text { Complication from } C \text {. difficile } \\
\text { infection }\end{array}$ & $12(2.2)$ & $14(3.0)$ & $10(1.8)$ & $3(0.6)$ & $9(1.7)$ & $12(2.3)$ & $11(2.6)$ & $71(2.0)$ \\
\hline Colectomy & $9(1.6)$ & $9(2.4)$ & $6(1.1)$ & $9(1.7)$ & $5(0.9)$ & $8(1.6)$ & $5(1.3)$ & $51(1.3)$ \\
\hline \multicolumn{9}{|l|}{ Patient status $\ddagger$} \\
\hline Discharged or transferred & $317(57.1)$ & $255(55.1)$ & $306(55.0)$ & $308(58.7)$ & $326(60.4)$ & $305(59.6)$ & $269(64.8)$ & $2086(58.5)$ \\
\hline Remained in hospital & $157(28.3)$ & $148(32.0)$ & $167(30.0)$ & $149(28.4)$ & $149(27.6)$ & $144(28.1)$ & $88(21.2)$ & $1002(281)$ \\
\hline Death (all cause) & $81(14.6)$ & $60(13.0)$ & $84(15.1)$ & $68(13.0)$ & $65(12.0)$ & $63(12.3)$ & $58(14.0)$ & 479 (13.4) \\
\hline $\begin{array}{l}\text { Death attributable to C. difficile } \\
\text { infection }\end{array}$ & $13(2.3)$ & $26(5.6)$ & $36(6.5)$ & $24(4.6)$ & $21(3.9)$ & $22(4.3)$ & $16(3.9)$ & $158(4.4)$ \\
\hline
\end{tabular}


associated $C$. difficile infection. The rate peaked (mostly driven by sites in the central region) at 6.7/10000 patient-days in 2011 and reached a nadir of 4.3/10000 patient-days in 2015 (Figure 1), representing a $35.8 \%$ relative decrease in the national rate. This same trend was noted in both western and central Canada. Rates of health care-associated $C$. difficile infection in eastern Canada (2.8/10000 patient-days) have remained lower than the national average (5.4/10000 patient-days) across the surveillance period $(p<0.001)$.

Completed standardized data collection forms were received for 17202 adults, and 2690 of these had molecular typing and reference susceptibility testing undertaken. Adult patients without data collection forms submitted (3075/20623) and pediatric patients (346/20623) were excluded (Table 1$)$.

Patient characteristics, laboratory findings and outcomes, by year and in aggregate, are shown in Table 1 . Men and women were equally represented. Over the 7-year period, the mean age of adults with health care-associated $C$. difficile infection was 69.2 years; $34.2 \%$ were between 18 and 64 years of age, and $65.8 \%$ were 65 years of age or older. There was a significant reduction in the age of patients with $C$. difficile infection over time, with younger adults representing an increasing proportion of reported cases $(p=0.02)$. The time, in days, from admission to a positive result on $C$. difficile testing was shorter in later years $(p=0.002)$. There were no significant trends over time noted in temperature, leukocyte counts, albumin levels or severe outcomes (death, admission to the intensive care unit [ICU] or colectomy). There was a significant increase over the study period in the proportion of patients discharged or transferred by day 30 , and a concomitant reduction of those remaining in hospital at that time point, whereas there were no significant changes over time in the rate of complications (death, ICU admission or colectomy).

Of the 2690 isolates that were available for molecular characterization and antimicrobial susceptibility testing, the top 3 most prevalent C. difficile NAP types were NAP1 (37.6\%), NAP4 (14.2\%) and NAP11 (5.9\%), accounting for $57.7 \%$ of all tested isolates nationally. A total of $18.6 \%$ were classified as either NAP2, NAP3, NAP5-10 or NAP12, whereas the remaining $23.7 \%$ of the isolates could not be assigned to a currently defined NAP type. Regionally, NAP1 was the most prevalent strain overall in the central (47.5\%) and western (30.1\%) regions,

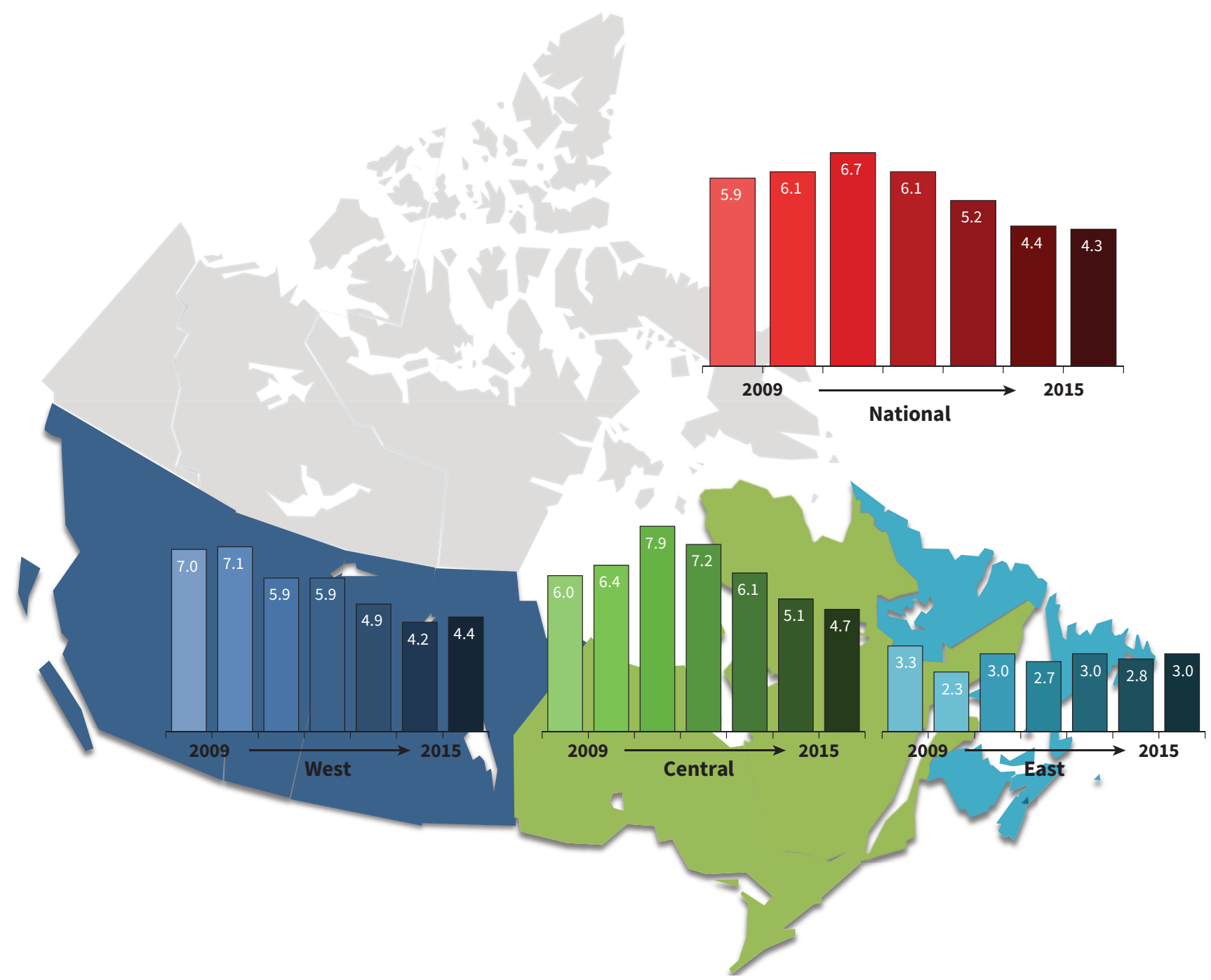

Figure 1: National (not including the territories) and regional rates of health care-associated Clostridium difficile infection in adults per 10000 patientdays from 2009 to 2015. West = British Columbia, Alberta, Saskatchewan and Manitoba; central = Ontario and Quebec; east = Nova Scotia, New Brunswick, Prince Edward Island, and Newfoundland and Labrador. 
but NAP4 was the most common strain type in the eastern region (24.1\%). Over the 7-year study period, there were significant changes in the molecular epidemiology of $C$. difficile both nationally and regionally, which included increases in NAP4, NAP6 and NAP11, as well as significant decreases in NAP2 and NAP1 (Table 2).

Overall, $44.5 \%, 28.4 \%$, and $1.5 \%$ of the $C$. difficile isolates tested were resistant to moxifloxacin, clindamycin and rifampin, respectively. Resistance to moxifloxacin has decreased significantly, from $63.3 \%$ in 2009 to $34.3 \%$ in 2015 ( $p<0.001$ ), and coincided with the decreasing prevalence of NAP1 isolates, which were predominantly moxifloxacin-resistant (956/1011 [94.6\%]). There was no in vitro resistance observed to tigecycline and metronidazole, but there was 1 NAP1 isolate identified with a minimum inhibitory concentration of $24 \mu \mathrm{g} / \mathrm{mL}$ to vancomycin.

Among participating hospitals, NAP1 strains, as a proportion of all submitted isolates, varied year-to-year (range $0 \%$ to 100\%). Patients infected with the NAP1 strain, compared with all other strains, were significantly older (74.0 v. $67.8 \mathrm{yr}, p<0.001$ ), had higher median leukocyte counts ( 13.0 v. $\left.10.8 \times 10^{9} / \mathrm{L}, p<0.001\right)$, a higher overall death rate $(15.6 \%$ v. $10.6 \%, p<0.001)$ and a higher death rate attributable to $C$. difficile infection $(6.6 \%$ v. $2.9 \%, p<0.001)$. In general, both allcause mortality and mortality attributable to $C$. difficile infection increased with age in particular; mortality among patients infected with all strains increased from $6.1 \%$ in the group aged $18-64$ years to $19.7 \%$ in the group aged 85 years or older (test for trend $p<0.001$ ). Mortality attributable to $C$. difficile infection among patients infected with all strains increased from $4.3 \%$ in the group aged $18-64$ years to $9.6 \%$ in the group aged 85 years or older (test for trend $p<0.001$ ). Among patients aged 75-84 years, NAP1 strains resulted in higher overall death rates than non-NAP1 strains $(19.3 \%$ v. $12.3 \%, p=0.01)$ as well as mortality attributable to $\mathrm{C}$. difficile infection $(12.2 \% \mathrm{v} .1 .4 \%$, $p<0.001)$. Those aged 85 years and older showed no significant differences in all-cause death or death attributable to $C$. difficile infection in the comparison of NAP1 and non-NAP1 strains (Table 3).

Table 4 presents the results from the analyses to identify independent associations between the outcomes and each of the strain types and covariates. The results from simple bivariable tests of association of each factor are presented in the "unadjusted" column, and the results from the full multivariable logistic regression analysis adjusting for all covariates are presented in the "adjusted" column. In multivariable analysis, the NAP1 strain was significantly associated with death attributable to $C$. difficile infection (adjusted odds ratio $1.91,95 \% \mathrm{Cl} 1.29-2.82$ ). Age and leukocyte count ( $\geq 15 \mathrm{v}$. $<15 \times 10^{9} / \mathrm{L}$ ) also remained significantly associated with death attributable to $C$. difficile infection (age: adjusted odds ratio 2.45 , $95 \% \mathrm{Cl}$ 1.44-4.16; leukocyte count: adjusted odds ratio $2.96,95 \% \mathrm{Cl}$ 2.01-4.35). There was no significant association between NAP strain type (NAP1 v. non-NAP1) and all-cause death (Table 4).

An association was noted between the proportion of circulating NAP1 strains within individual centres and their associated rates of health care-associated $C$. difficile infection. We noted that for every $10 \%$ increase in the proportion of NAP1 among all C. difficile strains submitted by individual centres, the rate of health care-associated C. difficile infection increased by $3.3 \%$ (95\% Cl 1.7\%-4.9\%).

\section{Interpretation}

Over a 7-year period, we observed a notable reduction in the national rate of health care-associated $C$. difficile infection and regional reductions in the rates in the central and western parts of the

Table 2: National (not including the territories) distribution of Clostridium difficile strain types among adults diagnosed with health care-associated C. difficile infection from 2009 to $2015^{*}$

\begin{tabular}{|c|c|c|c|c|c|c|c|c|c|}
\hline \multirow[b]{2}{*}{$\begin{array}{l}\text { NAP } \\
\text { strain }\end{array}$} & \multicolumn{7}{|c|}{ Year; no. $(\%)$ of patients } & \multirow[b]{2}{*}{$p$ valuet } & \multirow[b]{2}{*}{ Trend $\neq$} \\
\hline & $\begin{array}{c}2009 \\
n=379\end{array}$ & $\begin{array}{c}2010 \\
n=352\end{array}$ & $\begin{array}{c}2011 \\
n=384\end{array}$ & $\begin{array}{c}2012 \\
n=388\end{array}$ & $\begin{array}{c}2013 \\
n=412\end{array}$ & $\begin{array}{c}2014 \\
n=385\end{array}$ & $\begin{array}{c}2015 \\
n=390\end{array}$ & & \\
\hline NAP1 & $178(47.0)$ & $173(49.1)$ & $142(37.0)$ & $149(38.4)$ & $148(35.9)$ & $110(28.6)$ & $111(28.5)$ & $<0.001$ & $\downarrow$ \\
\hline NAP2 & $48(12.7)$ & $16(4.5)$ & $12(3.1)$ & $14(3.6)$ & $7(1.7)$ & $5(1.3)$ & $11(2.8)$ & $<0.001$ & $\downarrow$ \\
\hline NAP5 & $1(0.3)$ & $1(0.3)$ & $1(0.3)$ & $0(0.0)$ & $1(0.2)$ & $1(0.3)$ & $0(0.0)$ & Not tested & \\
\hline NAP6 & $14(3.7)$ & $10(2.8)$ & $17(4.4)$ & $22(5.7)$ & $17(4.1)$ & $18(4.7)$ & $26(6.7)$ & 0.03 & $\uparrow$ \\
\hline NAP7 & $2(0.5)$ & $12(3.4)$ & $6(1.6)$ & $6(1.5)$ & $12(2.9)$ & $11(2.9)$ & $9(2.3)$ & Not tested & \\
\hline NAP8 & $5(1.3)$ & $1(0.3)$ & $4(1.0)$ & $0(0.0)$ & $1(0.2)$ & $1(0.3)$ & $1(0.3)$ & Not tested & \\
\hline NAP11 & $4(1.1)$ & $6(1.7)$ & $16(4.2)$ & $23(5.9)$ & $21(5.1)$ & $52(13.5)$ & $36(9.2)$ & $<0.001$ & $\uparrow$ \\
\hline NAP12 & $5(1.3)$ & $7(2.0)$ & $14(3.6)$ & $13(3.4)$ & $10(2.4)$ & $13(3.4)$ & $9(2.3)$ & Not tested & \\
\hline
\end{tabular}


country. We also note significant changes in the strains of $C$. difficile circulating in Canadian hospitals over time, as reported in other institutions and regions. ${ }^{12,16,17}$ Although NAP1 remained the predominant strain throughout the surveillance period, a substantial reduction in the prevalence of NAP1 was noted with concomitant increases in the proportions of other strains (predominantly NAP4), which coincides with reports from the United States ${ }^{18}$ and the United Kingdom. ${ }^{19}$ These changes are notable as we also found strong associations between infection with NAP1 and attributable mortality, as well as associations between the proportion of NAP1 isolates circulating in individual hospitals and the local institutional rate of health careassociated $C$. difficile infection. Whereas mortality increased with age and was generally higher in patients with NAP1 strains, the rate of deaths attributable to $C$. difficile infection was found to be similar for NAP1 and non-NAP1 strains in patients aged 85 years and older. This may be related to the frail nature of these patients and the morbidity of any infection, regardless of the causative strain. ${ }^{5}$ The decrease in national rates of health care-associated $C$. difficile infection may be attributable, in large part, to a variety of infection-control and quality-improvement initiatives instituted at facilities across the

Table 3: Comparison of patients infected with NAP1 versus non-NAP1 strains, by demographic and clinical characteristics, and severe outcomes*

\begin{tabular}{|c|c|c|c|c|}
\hline \multirow[b]{2}{*}{ Variable } & \multicolumn{3}{|c|}{ Strain; no. (\%) of patients †‡ } & \multirow[b]{2}{*}{$p$ valueף } \\
\hline & $\begin{array}{c}\text { All strains } \\
n=2690\end{array}$ & $\begin{array}{c}\text { NAP1 } \\
n=1011\end{array}$ & $\begin{array}{c}\text { Non-NAP1§ } \\
n=1679\end{array}$ & \\
\hline Sex, female & $1351(50.4)$ & $502(49.9)$ & $849(50.8)$ & 0.6 \\
\hline Age, $y r$, mean \pm SD & $70.1 \pm 17.1$ & $74.0 \pm 14.8$ & $67.8 \pm 17.9$ & $<0.001$ \\
\hline \multicolumn{5}{|l|}{ Age group, yr } \\
\hline $18-64$ & $870(32.3)$ & $241(23.8)$ & $629(37.5)$ & $<0.001$ \\
\hline$\geq 65$ & $1818(67.6)$ & $769(76.1)$ & $1049(62.5)$ & $<0.001$ \\
\hline Unknown & $2(0.1)$ & $1(0.1)$ & $1(0.1)$ & Not tested \\
\hline \multicolumn{5}{|l|}{ Laboratory results } \\
\hline Temperature, ${ }^{\circ} \mathrm{C}$, mean $\pm \mathrm{SD}$ & $37.1 \pm 0.8$ & $37.1 \pm 0.7$ & $37.1 \pm 0.8$ & 0.9 \\
\hline Leukocyte count, $\times 10^{9} / \mathrm{L}$, median (IQR) & $11.6(7.8-16.9)$ & $13.0(8.9-19.1)$ & $10.8(7.2-15.9)$ & $<0.001$ \\
\hline Albumin, g/L, median (IQR) & $26.0(21.3-30.0)$ & $26.0(21.0-30.0)$ & $26.0(22.0-31.0)$ & 0.6 \\
\hline \multicolumn{5}{|l|}{ ICU admission } \\
\hline All-cause & $142(5.4)$ & $58(5.8)$ & $84(5.1)$ & 0.5 \\
\hline Complication from C. difficile infection & $43(1.6)$ & $27(2.7)$ & $16(1.0)$ & 0.001 \\
\hline Colectomy & $34(1.3)$ & $18(1.8)$ & $16(1.0)$ & 0.07 \\
\hline \multicolumn{5}{|l|}{ Outcome } \\
\hline Discharged or transferred & $1550(59.2)$ & $552(55.5)$ & $998(61.5)$ & 0.002 \\
\hline Remained in hospital & $723(27.6)$ & $286(28.1)$ & $437(26.9)$ & 0.3 \\
\hline All-cause death, age, yr & $327(12.5)$ & $155(15.6)$ & $172(10.6)$ & $<0.001$ \\
\hline $18-64$ & $51(6.1)$ & $17(7.2)$ & $34(5.7)$ & 0.4 \\
\hline $65-74$ & $60(11.5)$ & $22(12.5)$ & $38(10.9)$ & 0.6 \\
\hline $75-84$ & $103(15.5)$ & $59(19.3)$ & $44(12.3)$ & 0.01 \\
\hline$\geq 85$ & $113(19.7)$ & $57(20.8)$ & $56(18.7)$ & 0.5 \\
\hline $\begin{array}{l}\text { Death attributable to } C \text {. difficile infection, } \\
\text { age, yr }\end{array}$ & $113(4.3)$ & $66(6.6)$ & $47(2.9)$ & $<0.001$ \\
\hline $18-64$ & $17(2.0)$ & $9(3.8)$ & $8(1.3)$ & 0.04 \\
\hline $65-74$ & $14(2.7)$ & $8(4.5)$ & $6(1.7)$ & 0.08 \\
\hline $75-84$ & $30(4.5)$ & $25(12.2)$ & $5(1.4)$ & $<0.001$ \\
\hline$\geq 85$ & $52(9.6)$ & $24(8.8)$ & $28(9.3)$ & 0.8 \\
\hline Unknown & $17(0.7)$ & $2(0.2)$ & $15(0.9)$ & Not tested \\
\hline
\end{tabular}


country after major outbreaks 10-15 years ago (e.g., improved diagnostic techniques; antibiotic stewardship, particularly in regard to fluoroquinolone use; improved hand-hygiene practices; increased quality and frequency of environmental cleaning; increased use of sporicidal cleaning agents; and public reporting of institutional rates of health care-associated $C$. difficile infection), but our findings also support the concept that part of the improvement in institutional rates relates to the regression of predominance of the NAP1 strain.

The NAP1 strain, in particular, has been found to be associated with a risk of facility-wide and regional epidemics or outbreaks after its emergence. ${ }^{6,20-22}$ What is less clear is the impact of NAP1 on the severity of disease in nonepidemic settings, ${ }^{9-11}$ and whether (or to what extent) NAP1 leads to a higher baseline institutional rate of health care-associated $C$. difficile infection in nonepidemic settings. Despite the finding that recent NAP1 strains continue to produce a large amount of toxin, studies at single centres and at a provincial level have not demonstrated an association between the NAP1 strain and severe disease in a nonoutbreak setting. ${ }^{9-11}$ In our large Canadian cohort of acute care hospitals during a nonepidemic period, we note a strong association between the NAP1 strain type (compared with all other strain types) and death attributable to $C$. difficile infection in patients $18-85$ years. In concordance with a previous report, ${ }^{5}$ there was no significant difference found for the rate of death attributable to $C$. difficile infection between NAP1 and non-NAP1 strains for patients aged 85 years and above, which were both high at $8.8 \%$ and $9.3 \%$, respectively (Table 4). Hospitals frequently benchmark their rates of health care-associated $C$. difficile infection to prior years at the same institution, or to other local or regional hospitals of a similar size or where the scope of services offered is similar. Our findings suggest that, as the proportion of NAP1 strain isolates increases in relation to all circulating strains, both the rate of health care-associated $C$. difficile infection and the number of severe cases can be expected to increase relative to a peer hospital with a lower proportion of NAP1 circulating isolates. We are not aware of published work that quantifies the impact of a higher circulating proportion of NAP1 isolates on local hospital rates of health careassociated $C$. difficile infection in nonepidemic settings.

\section{Limitations}

There are limitations to our study, inherent to large multicentre surveillance activities. First, although data collection was conducted by experienced and trained infection-control professionals using standardized definitions that incorporate clinical symptoms, the data collection was unmonitored and there may be inconsistencies between hospitals in identifying a case of $C$. difficile infection or applying the definition of "health care-associated event." Because the diagnosis of a $C$. difficile infection is frequently based on laboratory findings, there may be some variability in the microbiological laboratory testing and identification of $C$. difficile at the different hospitals. Pediatric cases could not be differentiated from adult cases in the rate calculations among mixed hospitals; however, these comprised less than $2 \%$ of total cases of health care-associated $C$. difficile infection across the years and were excluded from further analyses.

In addition, although the hospital epidemiologist or another qualified physician determined the cause of death in patients with health care-associated $C$. difficile infection; attribution of death is often difficult and may be subjective. Finally, the group

Table 4: Analyses of variables associated with all-cause death and death attributable to Clostridium difficile infection

\begin{tabular}{|c|c|c|c|c|}
\hline \multirow[b]{2}{*}{ Variable } & \multicolumn{2}{|c|}{ All-cause death } & \multicolumn{2}{|c|}{ Death attributable to $C$. difficile infection } \\
\hline & OR $(95 \% \mathrm{CI})^{\star}$ & Adjusted OR $(95 \% \mathrm{CI}) \dagger$ & OR $(95 \% \mathrm{Cl})^{\star}$ & Adjusted OR $(95 \% \mathrm{CI}) \dagger$ \\
\hline Female & 1.00 (ref.) & 1.00 (ref.) & 1.00 (ref.) & 1.00 (ref.) \\
\hline Male & $1.07(0.85-1.35)$ & $1.15(0.91-1.46)$ & $1.25(0.85-1.82)$ & $1.34(0.91-1.97)$ \\
\hline$\geq 65$ & $2.86(2.09-3.90)$ & $2.73(1.99-3.74)$ & $2.78(1.65-4.68)$ & $2.45(1.44-4.16)$ \\
\hline \multicolumn{5}{|c|}{ NAP strain type } \\
\hline Non-NAP1 & 1.00 (ref.) & 1.00 (ref.) & 1.00 (ref.) & 1.00 (ref.) \\
\hline NAP1 & $1.54(1.22-1.95)$ & $1.26(0.99-1.60)$ & $2.36(1.51-3.47)$ & $1.91(1.29-2.82)$ \\
\hline \multicolumn{5}{|c|}{ Albumin level, g/L } \\
\hline$>30$ & 1.00 (ref.) & - & 1.00 (ref.) & - \\
\hline$\leq 30$ & $2.03(1.31-3.14)$ & - & $4.46(1.77-11.26)$ & - \\
\hline
\end{tabular}


of participating facilities overrepresents larger teaching hospitals and does not include Canadian territories, thus is not likely fully representative of all hospital-admitted adult patients in Canada.

\section{Conclusion}

Rates of health care-associated $C$. difficile infection have fallen across Canada from 2009 to 2015. Although the NAP1 strain was associated with attributable death in nonepidemic settings, the reduction in the proportion of NAP1 isolates has likely contributed to the improvement in local and national institutional rates of health care-associated $C$. difficile infection. Infection prevention and control practices, antimicrobial stewardship and environmental cleaning should continue to be strengthened at the local level, as these areas positively affect institutional rates of health careassociated $C$. difficile infection, regardless of circulating strain types.

\section{References}

1. Cohen SH, Gerding DN, Johnson S, et al. Clinical practice guidelines for Clostridium difficile infection in adults: 2010 update by the Society for Healthcare Epidemiology of America (SHEA) and the Infectious Diseases Society of America (IDSA). Infect Control Hosp Epidemiol 2010;31:431-55.

2. Polage CR, Solnick JV, Cohen SH. Nosocomial diarrhea: evaluation and treatment of causes other than Clostridium difficile. Clin Infect Dis 2012;55:982-9.

3. Loo VG, Poirier L, Miller MA, et al. A predominantly clonal multi-institutional outbreak of Clostridium difficile-associated diarrhea with high morbidity and mortality. N Engl J Med 2005;353:2442-9.

4. Denève $C$, Janoir C, Poilane I, et al. New trends in Clostridium difficile virulence and pathogenesis. Int J Antimicrob Agents 2009;33(suppl 1):S24-8.

5. Miller M, Gravel D, Mulvey M, et al. Health care-associated Clostridium difficile infection in Canada: patient age and infecting strain type are highly predictive of severe outcome and mortality. Clin Infect Dis 2010;50:194-201.

6. Freeman J, Bauer MP, Baines SD, et al. The changing epidemiology of Clostridium difficile infections. Clin Microbiol Rev 2010;23:529-49.
7. See I, Mu Y, Cohen J, et al. NAP1 strain type predicts outcomes from Clostridium difficile infection. Clin Infect Dis 2014;58:1394-400.

8. Rao K. Measuring the impact of Clostridium difficile infection with the NAP1 strain on severity and mortality. Clin Infect Dis 2014;59:1193-4.

9. Sirard S, Valiquette L, Fortier LC. Lack of association between clinical outcome of Clostridium difficile infections, strain type, and virulence-associated phenotypes. J Clin Microbiol 2011;49:4040-6.

10. Cloud J, Noddin L, Pressman A, et al. Clostridium difficile strain NAP-1 is not associated with severe disease in a nonepidemic setting. Clin Gastroenterol Hepatol 2009;7:868-873.e2.

11. Scardina T, Labuszewski L, Pacheco SM, et al. Clostridium difficile infection (CDI) severity and outcome among patients infected with the NAP1/BI/027 strain in a non-epidemic setting. Infect Control Hosp Epidemiol 2015;36:280-6.

12. Cairns MD, Stabler RA, Shetty N, et al. The continually evolving Clostridium difficile species. Future Microbiol 2012;7:945-57.

13. Quesada-Gómez C, López-Ureña D, Acuña-Amador L, et al. Emergence of an outbreak-associated Clostridium difficile variant with increased virulence. J Clin Microbiol 2015;53:1216-26.

14. Rutledge-Taylor K, Mitchell R, Pelude L, et al. Evaluation of the representativeness of the Canadian Nosocomial Infection Surveillance Program. Can J Infect Control 2015;2015:13-7.

15. Gravel D, Miller M, Simor A, et al. Health care-associated Clostridium difficile infection in adults admitted to acute care hospitals in Canada: a Canadian nosocomial infection surveillance program study. Clin Infect Dis 2009;48:568-76.

16. Freeman J, Vernon J, Morris K, et al. Pan-European longitudinal surveillance of antibiotic resistance among prevalent Clostridium difficile ribotypes. Clin Microbiol Infect 2015;21:248.e9-16.

17. Knight DR, Elliott B, Chang BJ, et al. Diversity and evolution in the genome of Clostridium difficile. Clin Microbiol Rev 2015;28:721-41.

18. Tickler IA, Goering RV, Whitmore JD, et al. Strain types and antimicrobial resistance patterns of Clostridium difficile isolates from the United States, 2011 to 2013. Antimicrob Agents Chemother 2014;58:4214-8.

19. Clostridium difficile ribotyping network (CDRN) for England and Northern Ireland 2013-2015. London (UK): Public Health England; 2016.

20. Kuijper EJ, Coignard B, Brazier JS, et al. Update of Clostridium difficile-associated disease due to PCR ribotype 027 in Europe. Euro Surveill 2007;12:E1-2.

21. Lessa FC, Gould CV, Clifford McDonald L. Current status of Clostridium difficile infection epidemiology. Clin Infect Dis 2012;55(Suppl 2):S65-70.

22. Barbut F, Jones G, Eckert C. Epidemiology and control of Clostridium difficile infections in healthcare settings: an update. Curr Opin Infect Dis 2011;24:370-6.

\begin{abstract}
Competing interests: Andrew Simor reports honoraria from Merck Canada. Yves Longtin reports grants from Merck and Becton Dickinson. No other competing interests were declared.
\end{abstract}

This article has been peer reviewed.

Affiliations: North York General Hospital (Katz), Toronto, Ont.; National Microbiology Laboratory (Golding, Du, Mulvey), Winnipeg, Man.; Public Health Agency Canada (Choi, Pelude, Amaratunga, Alexandre, Gravel), Ottawa, Ont.; Ottawa Hospital Research Institute (Taljaard), Ottawa, Ont.; BC Children's Hospital, BC Women's Hospital (Collet), Vancouver, BC; Queen Elizabeth II Health Sciences Centre (Davis), Halifax, NS; Kingston General Hospital (Evans), Kingston, Ont.; McGill University Health Centre (Frenette), Montréal, Que.; University Health Network (Hota, Lemieux), Toronto, Ont.; Royal Jubilee Hospital (Kibsey), Victoria, BC; IWK Health Centre (Langley), Halifax, NS; Stollery Children's Hospital (Lee), Edmonton, Alta.; Jewish General Hospital (Longtin), Montréal, Que.; Hamilton Health Sciences (Mertz), Hamilton, Ont.; Mount Sinai Hospital (Maze Dit Mieusement), Toronto, Ont.; Regina General Hospital (Minion), Regina, Sask.; Montreal Children's Hospital (Moore),
Montréal, Que.; The Hospital for Sick Children (Richardson, Science), Toronto, Ont.; Sunnybrook Health Sciences Centre (Simor), Toronto, Ont.; Western Memorial Regional Hospital (Stagg), Corner Brook, NL; The Ottawa Hospital (Suh, Amaratunga), Ottawa, Ont.; University of Alberta Hospital (Taylor), Edmonton, Alta., Royal University Hospital (Wong), Saskatoon, Sask.; Children's Hospital of Eastern Ontario (Thampi), Ottawa, Ont.

Contributors: George Golding and Kelly Baekyung Choi contributed equally as coauthors. All of the authors made substantial contributions to the design of the work and interpretation of the data. Kevin Katz, Kelly Baekyung Choi, Kanchana Amaratunga, Nisha Thampi, George Golding and Linda Pelude contributed to the acquisition and analysis of data. All of the authors drafted and critically revised the work, approved the final version to be published and agreed to be accountable for all aspects of the work.

Funding: Kevin Katz, Bonita Lee, Tim Du, Susy Hota, Dominik Mertz, Susan Richardson, Kathryn Suh and Geoffrey Taylor report funding from the Public Health Agency of Canada to support surveillance activity.
Data sharing: Study protocols are available. Data sharing requests will be considered and reviewed by the Public Health Agency of Canada and individual site investigators.

Acknowledgements: The authors thank Romeo Hizon and Sean Ahmed from the National Microbiology Laboratory for the isolation of $C$. difficile from stool specimens, antimicrobial susceptibility testing and molecular typing, and Jennifer Campbell for the lab isolate and data follow-up. They thank Katie Cassidy, Micheline Smith, Jacob Miller, Nana Boame, Cassandra Lybeck and Meghan Laverty from the Canadian Nosocomial Infection Surveillance Program Ottawa team for their data management and quality, and The Minh Luong for assistance with the manuscript. The authors gratefully acknowledge the contribution of the epidemiologists, infection-control practitioners and staff for their data and lab collection and submission at each participating hospital.

Accepted: Apr. 6, 2018

Correspondence to: Kevin Katz, Kevin.Katz@ nygh.on.ca 